\title{
Knowledge of Cervical Cancer and Its Screening Amongst Female Students of a Tertiary Institution in South-South Nigeria
}

\author{
D. O. Allagoa, O. J. Agbo, A. O. Eguvbe, and P. W. Alabra
}

\section{ABSTRACT}

Background: Cervical cancer is one of the commonest cancers in women. It is the commonest cause of cancer related death in Africa. It is one of the cancers that have well known screening methods. In developed societies with standard protocol for screening, the morbidity and mortality following the disease have been greatly reduced. There is paucity of knowledge of cervical cancer and its screening methods in Yenagoa.

Objectives: To determine the knowledge of cervical cancer and its screening methods in female students of a Tertiary educational institution.

Methods: This was a cross-sectional descriptive study that was conducted amongst the female students of Federal University Otuoke. Information about their socio-demographic characteristics, knowledge of cervical cancer and the screening methods was obtained using a questionnaire.

Results: A total of four hundred and twenty four (424) female students of the Federal University Otuoke were enrolled for the study. The mean age of the respondents was 21.0 \pm 3.4 years. The predominant age group was 15-20 years $(50.6 \%)$. One hundred and eighty three respondents $(57.9 \%)$ were aware of cervical cancer and the age groups 21-25 years were most aware of cervical cancer. Age was found to influence awareness of cervical cancer. $(\mathrm{x} 2=12.8 ; \mathrm{df}=3 ; \mathrm{p}<0.05)$. A total of eighty one respondents $26.9 \%$ were aware of Pap smear. Age was found to influence the awareness of Pap smear $(x 2=12.8 ; d f=3 ; p<0.05)$.

Conclusion: Our study showed that awareness of cervical cancer and the role of Pap smear in the screening of cervical cancer was low amongst the female students of the Federal University Otuoke. Hence the need to make every effort to increase the awareness of this condition and the screening methods amongst these female undergraduates, who are at the prime of their age and at the greatest risk of developing this condition, especially in our societies that lack well organized screening protocols.

Keywords: cervical cancer, Pap smear, screening.
Published Online: November 16, 2020

ISSN: 2593-8339

DOI: $10.24018 /$ ejmed.2020.2.6.530

D. O. Allagoa

BMedsc (Pharm) MBBS, FWACS, FMAS, DMAS, CERT ART, Dip HMS, FICS, Consultant Obstetrician , Gynaecologist, Federal Medical Centre Yenagoa, Bayelsa State, Nigeria.

O. J. Agbo*

MBBS, FWACS, Consultant Obstetrician / Gynaecologist, Federal Medical Centre Yenagoa, Bayelsa State, Nigeria. (e-mail: agbodrjohn@yahoo.com) A. O. Eguvbe

MBBS, FWACS, Consultant epidemiologist/ public health physician, Federal Medical Centre Yenagoa, Bayelsa State, Nigeria.

P. W. Alabra

MBBS, FWACS, Consultant Obstetrician / Gynaecologist, Federal Medical Centre Yenagoa, Bayelsa State, Nigeria.

*Corresponding Author

\section{INTRODUCTION}

Cervical cancer is the second most common cancer in women world-wide and the commonest in developing countries [1]. The availability of well organized screening protocols in developed societies has greatly reduced the morbidity and mortality associated with cervical cancer over the years2. However, the story is different in developing countries where the burden of the diseases is greatly felt [1], [2]. Each year there are approximately 500,000 new cases of cervical cancer of which over $80 \%$ are found in developing societies and over 300,000 deaths from the diseases [3], [4].

The most important risk factor for cervical cancer in developing countries is infrequent screening or lack of accessible cervical cancer services and infection with a high-risk strain of human papilloma virus [5]. Other risk factors include early age at sexual intercourse, early marriage, multiple sexual partners, grandmultiparity, multiple marriage, low socio-economic status, use of oral contraceptives and immunosuppression [2], [4], [6].

Screening helps to identify women with premalignant lesions or those with early stage diseases and allow the commencement of treatment and follow-up [7]. The use of Pap smear as a screening tool in developed societies have led to a reduction in the burden of the disease in such societies [1], [2]. There are other common and less cumbersome methods like visual inspection with acetic acid (VIA) and visual inspection with lugos iodine (VILI). These 
methods of screening are simple, less costly and require minimal training. However, these methods are less sensitive when compared with Pap smear [7]. Other screening methods include the use of liquid base cytology and HPVDNA testing [8].

The uptake of cervical screening in Abakaliki south-east Nigeria is $10.1 \%$ and in Lagos south-west Nigeria is $5.1 \%$ [9]. The uptake of cervical cancer screening in Ethiopia is $3 \%$ [10]. The screening rate for cervical cancer in the United Kingdom is $71.4 \%$ and $77.5 \%$ in United State of American [11], [12]. The uptake for cervical cancer screening is higher in the developed societies. Hence the higher morbidity and mortality associated with the diseases in our societies.

There are certain barriers associated with the low uptake of cervical cancer in our societies these include poor infrastructures, lack of trained staffs, poor knowledge about cervical cancer and illiteracy [13]-[15]. These barriers notwithstanding, it is important to note that the success made in the reduction of morbidity and mortality associated with this condition in the developed countries can be repeated in our societies. It is true developing societies have other contending health needs however what is required to eliminate these barriers is creating awareness about the problem among those who are at the greatest risk of developing the diseases and specific interventions by Governments in the developing countries.

Cancer of the cervix can be prevented by providing widespread and regular cervical cancer screening services for all women who are sexually active [14], [15]. However, the success of the screening depends largely on the knowledge and attitude of the general public, especially young women in our tertiary educational institution about cervical cancer and the various screening modalities especially Pap smear. Young women are the populations at the greatest risk of developing cervical cancer especially in our societies, where there are no well organized screening protocols rather opportunistic screening services is the norm. Hence this study aimed to determine the knowledge and attitude of female studies in a tertiary educational institution towards cervical cancer and its screening methods.

\section{METHODOLOGY}

\section{A. Study Area}

This study was conducted at the Federal University Otueke, in Ogbia Local Government area of Bayelsa state. The University has 5 faculties and 29 departments with student's population of about 3500 of which 2100 are female students. A total of 424 female students took part in the study. The ethical committee of the University gave the approval for the study.

\section{B. Study Design}

This was an institutional based descriptive study. In which questionnaires were administered to the eligible participants in the study. The questionnaires assessed the level of knowledge, awareness, and the screening methods for cervical cancer. Other information obtained included the socio-demographic characteristics of the study participants.

\section{Sample Size Determination}

One proportion sampling size with population greater than 10,000:

where

$$
\mathrm{n}=\mathrm{Z}^{2} \mathrm{pq} / \mathrm{d}^{2}
$$

$\mathrm{n}=$ the minimum sample size.

$\mathrm{z}=$ standard normal deviate, set at 1.96 corresponding to $95 \%$ significance level.

$\mathrm{P}=50 \%$ proportion of characteristics (attributes) in the population because there are no reports of previous studies on this in this area.

$\mathrm{q}=1-\mathrm{p}$.

$\mathrm{q}=1-0.5=0.5$.

$\mathrm{d}=$ precision or degree of accuracy i.e. acceptable margin of sample error set at $5 \%$ or 0.05 .

Substituting the above figures in the formula, the desired sample size, $n$, for the study will be:

$$
\mathrm{n}=(1.96)^{2} \times 0.5 \times 0.5 / 0.05^{2}=385
$$

This therefore means that a minimum sample size of 385 is required for the study to be valid.

Adjusting by $10 \%$ for non-response $n=424$ is now the sample size for the study.

\section{Statistical Analysis}

Consent to participate in this study was sought from the respondents after detailed explanation to them about what the study entails, as well as assuring them of confidentiality of the information to be given. The questionnaires were then self-administered to a total of 424 participants. The respondents were only guided in their responses when they voluntarily called for assistance.

The data obtained were analyzed using SPSS version 23. Test of association were done using Chi square statistics at $95 \%$ confidence levels.

\section{RESULTS}

A total number of four hundred and twenty four (424) female students of the Federal University, Otuoke were included in the study.

The socio-demographic characteristics of respondents are shown on Table 1. The mean age of respondents was $21.0 \pm 3.4$ years. The predominant age group was $15-20$ years (50.6\%); followed closely by age group 21-25 years 147 (44.3\%). Majority 167 (40.4\%) of the respondents were of the Ijaw ethnicity; followed by the Igbo ethnicity 119 (28.8\%). The respondents were predominantly Christians 408 (96.2\%), with denominations more of Pentecostal 234 (55.8\%), followed by Catholics 101 (24.1\%). All the respondents $(100 \%)$ were students but $22(5.2 \%)$ were employed. 
TABLE 1: SOCIO-DEMOGRAPHIC CHARACTERISTICS OF RESPONDENTS

\begin{tabular}{|c|c|c|}
\hline Variable & Frequency & Percentage \\
\hline \multicolumn{3}{|l|}{ Age in years $(n=332)$} \\
\hline $15-20$ & 168 & 50.6 \\
\hline $21-25$ & 147 & 44.3 \\
\hline $26-30$ & 5 & 1.5 \\
\hline $31-35$ & 12 & 3.6 \\
\hline \multicolumn{3}{|l|}{ Ethnicity $(n=413)$} \\
\hline Ijaw & 167 & 40.4 \\
\hline Igbo & 119 & 28.8 \\
\hline Hausa & 12 & 2.9 \\
\hline Yoruba & 33 & 8.0 \\
\hline Urhobo & 46 & 11.1 \\
\hline Edo & 12 & 2.9 \\
\hline Others & 24 & 5.8 \\
\hline \multicolumn{3}{|l|}{ Marital Status $(n=424)$} \\
\hline Single & 401 & 94.6 \\
\hline Married & 12 & 2.8 \\
\hline Separated & 11 & 2.6 \\
\hline \multicolumn{3}{|l|}{ Religion $(n=419)$} \\
\hline Christianity & 408 & 96.2 \\
\hline Islam & 11 & 2.6 \\
\hline \multicolumn{3}{|c|}{ Christian denominations $(n=408)$} \\
\hline Catholic & 101 & 24.1 \\
\hline Pentecostal & 234 & 55.8 \\
\hline Anglican & 57 & 13.6 \\
\hline Others & 16 & 3.8 \\
\hline \multicolumn{3}{|c|}{ If currently employed $(n=424)$} \\
\hline Yes & 22 & 5.2 \\
\hline Student & 402 & 94.8 \\
\hline
\end{tabular}

TABLE 2: AWARENESS OF CERVICAL CANCER

\begin{tabular}{lcccc}
\hline \multicolumn{1}{c}{ Variable } & Yes $(\%)$ & No $(\%)$ & $\begin{array}{c}\text { Test } \\
\text { statistics }\end{array}$ & $\begin{array}{c}\text { p } \\
\text { value }\end{array}$ \\
\hline $\begin{array}{l}\text { Age of respondents } \\
\text { in years }(\mathbf{n}=\mathbf{3 1 6})\end{array}$ & & & & \\
$15-20$ & $87(27.5)$ & $70(22.2)$ & $\mathrm{x}^{2}=12.79$ & 0.005 \\
$21-25$ & $89(28.2)$ & $58(18.4)$ & $\mathrm{df}=3$ & \\
$26-30$ & $0(0)$ & $5(1.6)$ & & \\
$31-35$ & $7(2.2)$ & $0(0)$ & & \\
Total & $\mathbf{1 8 3}(\mathbf{5 7 . 9})$ & $\mathbf{1 3 3}(\mathbf{4 2 . 1})$ & & \\
Religion $(\mathbf{n = 3 9 8 )}$ & & & & \\
Christianity & $241(60.6)$ & $146(36.7)$ & $\mathrm{x}^{2}=14.2$ & \\
Islam & $0(0$ & $11(2.8)$ & & \\
Ethnic group & & & & \\
(n=397) & & & & \\
Ijaw & $92(23.2)$ & $75(18.9)$ & $\mathrm{x}^{2}=22.4$ & \\
Igbo & $85(21.4)$ & $23(5.8)$ & $\mathrm{df}=6$ & \\
Hausa & $6(1.5)$ & $6(1.5)$ & & \\
Yoruba & $17(4.3)$ & $11(2.8)$ & & \\
Urhobo & $23(5.8)$ & $23(5.8)$ & & \\
Edo & $6(1.5)$ & $6(1.5)$ & & \\
Others & $11(2.8)$ & $13(3.3)$ & & \\
\hline
\end{tabular}

A total of 183 respondents (57.9\%) were aware of cervical cancer. The age group 21-25 years was most aware of cervical cancer (28.2\%); it was followed closely by the age group 15-20 with $87(27.5 \%)$ awareness of cervical cancer. The age group 15-20 years was most unaware of cervical cancer $70(22.2 \%)$. Age was found to influence awareness of cervical cancer $\left(\mathrm{x}^{2}=12.8 ; \mathrm{df}=3 ; \mathrm{p}<0.05\right)$. Majority of the respondents who were Christians were aware of cervical cancer $241(60.6 \%)$ and none of the respondents of the Islamic religion was aware of cervical cancer. This difference was found to be statistically significant $\left(\mathrm{x}^{2}=14.2 ; \mathrm{df}=1 ; \mathrm{P}<0.05\right)$.

Awareness of cervical cancer was 92 (23.1\%) amongst respondents of the Ijaw ethnic group; it was followed closely by the Igbo ethnic group with 85 (21.4\%). The other ethnic groups had a lower level of awareness of cervical cancer. Ethnic affiliation was found to significantly affect awareness of cervical cancer $\left(x^{2}=22.4 ; d f=6 ; p<0.05\right)$.
TABLE 3: KNOWLEDGE OF PAP SMEAR

\begin{tabular}{|c|c|c|c|c|}
\hline Variable & Yes $(\%)$ & No $(\%)$ & $\begin{array}{c}\text { Test } \\
\text { statistics }\end{array}$ & $\begin{array}{c}\mathbf{p} \\
\text { value }\end{array}$ \\
\hline \multicolumn{5}{|c|}{$\begin{array}{l}\text { Age of respondents } \\
\text { in years }(n=310)\end{array}$} \\
\hline $15-20$ & $30(9.7)$ & $121(39.0)$ & $x^{2}=12.89$ & 0.005 \\
\hline $21-25$ & $51(16.5)$ & $96(30.9)$ & $\mathrm{df}=3$ & \\
\hline $26-30$ & $0(0)$ & $5(1.6)$ & & \\
\hline $31-35$ & $0(0)$ & $7(2.3)$ & & \\
\hline Total & 81(26.1) & $229(73.9)$ & & \\
\hline \multicolumn{5}{|c|}{ Religion $(n=387$ ) } \\
\hline Christianity & $104(26.9)$ & $272(70.3)$ & $x^{2}=2.2$ & 0.1379 \\
\hline Islam & $0(0)$ & $11(2.8)$ & & \\
\hline \multicolumn{5}{|l|}{$\begin{array}{l}\text { Ethnic group } \\
(\mathbf{n}=\mathbf{3 8 6})\end{array}$} \\
\hline Ijaw & $31(8.0)$ & $131(33.9)$ & $x^{2}=21.9$ & 0.001 \\
\hline Igbo & $39(10.1)$ & $63(16.3)$ & $\mathrm{df}=6$ & \\
\hline Hausa & $0(0)$ & $12(3.1)$ & & \\
\hline Yoruba & $11(2.8)$ & $17(4.4)$ & & \\
\hline Urhobo & $12(3.1)$ & $34(8.8)$ & & \\
\hline Edo & $6(1.6)$ & $6(1.6)$ & & \\
\hline Others & $5(1.3)$ & $19(4.9)$ & & \\
\hline
\end{tabular}

A total of 81 respondents $(26.9 \%)$ were aware of pap smear. The age group 21-25 years was most aware of Pap smear $(16.5 \%)$; it was followed closely by the age group 15 20 with $30(9.7 \%)$ awareness of pap. The age group $15-20$ years was most unaware of pap smear 121 (39.0\%). Age was found to influence the lack of awareness of Pap smear $\left(\mathrm{x}^{2}=12.9 ; \mathrm{df}=3 ; \mathrm{p}<0.05\right)$. Christians had poor awareness of Pap smear 104 (26.9\%) and this poor awareness was more as compared to those of the Islamic religion who had no awareness. This difference was not found to be statistically significant $\left(\mathrm{x}^{2}=2.2 ; \mathrm{df}=1 ; \mathrm{P}>0.05\right)$.

Awareness of pap smear was 39 (10.1\%) amongst respondents of the Igbo ethnic group; it was followed closely by the Ijaw ethnic group with $31(8.0 \%)$. The other ethnic groups had a lower level of awareness of pap smear. Ethnic affiliation was found to significantly affect the low awareness of pap smear $\left(x^{2}=21.9 ; \mathrm{df}=6 ; \mathrm{p}<0.05\right)$.

\section{DISCUSSION}

Cervical cancer is the commonest cause of preventable gynecological cancer all over world especially in sub-Sahara Africa. This study was the first conducted to ascertain the knowledge of cervical cancer and its screening amongst female students of the Federal University Otueke. This is important considering the fact that young women in our societies are at the greatest risk of developing the condition. Besides there are no organized screening procedures in our societies and cervical cancer vaccines are not readily available and affordable.

The mean age group in this study was $21.0 \pm 3.4$ years. The study also showed that the predominant age group was 15 20 years (50.6). This is not surprising considering the fact that the study was conducted amongst female students of a tertiary educational center. A study was conducted in the Niger University: the mean age group was $38.80 \pm 9.05$ years [14]. In a similar study in Indian, the mean age group was $38.2 \pm 13.2$ years [15]. The disparity in the mean age group may be due to the fact that the Niger Delta and India studies in addition to female students had Lecturers and Teachers as participants. 
The most important finding in this study was the awareness for cervical cancer amongst the participants. The study showed that age was found to influence the awareness of cervical cancer. Our study revealed that 183 respondents $(57.9 \%)$ were aware of cervical cancer and the age group 21-25 years were most aware and 15-20 years most unaware. In a study conducted in Tanzania and amongst Sub-Saharan African students in United Kingdom there was similar findings [16], [17]. However, the Finding our study was at varies with the outcome in similar studies amongst Health workers in Delta state, south-south Nigeria and central region of Ghana that clearly showed that age was not found to influence the awareness of cervical cancer [18], [19].

Our study showed that a total of 13 respondents $(57.9 \%)$ were aware of cervical cancer. This is in keeping with the findings in similar study conducted amongst young literate University students in South Africa were the awareness was $55.2 \%$ [20]. The study conducted amongst semi-urban dwellers in Ghana the awareness for cervical cancer was $(31.6 \%)$ and lower value of $15 \%$ was obtained in a study conducted in Lagos, South West Nigeria [21], [22]. The disparity observed in the studies may be due the sociodemographic characteristic of the study participants since the study in Lagos and Ghana had rural dwellers as respondents.

This study showed that the awareness of Pap smear was $26.9 \%$. In a similar study conducted amongst students in Gabon, the awareness of Pap smear was 27.9\% [23]. However, in a study conducted amongst health workers in Maiduguri North-East Nigeria the awareness was 94\% and in another study amongst health workers the awareness was of Pap smear was $89.2 \%$ [24], [25]. This clearly showed that the awareness of Pap smear is higher amongst health workers. This shows clearly that health workers have a special role to play in creating awareness about cervical cancer and the use of Pap smears in cervical cancer screening.

\section{CONCLUSION}

This study highlighted the lack of awareness of cervical cancer and its' screening methods amongst the female students of the Federal University Otuoke. The study also showed that age influenced the awareness of cervical cancer and Pap smear. The importance of creating awareness of this highly preventable condition that has its' greatest burden in our societies cannot be over emphasized. Government at various levels and Heads of the Institution have a big role to play in reversing this ugly trend.

\section{REFERENCES}

[1] World Health Organization (WHO) fact sheets 380: Human papillomavirus (HPV) and cervical cancer. Geneva: World Health Organization.

[2] Ali F, Kuelker R, Wassie B. Understanding cervical cancer in the context of developing countries. Ann Trop Med Pub Health 2012; (1) $5: 3-15$.
[3] Ferlay J, Shin HR, Bray F, Forman D, Mathers C, Parkin DM. Estimates of worldwide burden of cervical cancer in 2008. Int J Cancer 2010; 127:2893-917.

[4] Nnadi DC, Nwobodo EI, Ekele BA, Sahabi SM. Screening for cervical cancer: A review of outcome among infertile women in a tertiary Hospital in North-West Nigeria. Ann Med Health Sci Res 2014; 4(3):383-387.

[5] Abiodun OA, Fatungase OK, OLu-Abiodun OO, Idowu-Ajiboye BA Awosile JO. An assessment of women's awareness and knowledge about cervical cancer screening and the barriers to cervical cancer in Ogun State, Nigeria. J Dent Med Sci 2013; 10(3):52-58.

[6] Holschneider $\mathrm{CH}$. Premalignant and malignant disorders of the cervix. In: DeCherney AH, Nathan L, Laufer N, Roman AS. Editors in: Current Diagnosis and Treatment Obsteterics and Gynaecology. 11th ed. New York: McGraw-Hill; 2013:807-831.

[7] Idowu A, Olowookere SA, Fagbemi AT, Ogunlaja A. Determinants of cervical cancer screening uptake among women in Ilorin, North Central Nigeria: A Community- based study. J Cancer Epid 2016;1-8

[8] Kitchener HC, Gilham C, Sargent A, Bailey A, Albrow R. A comparision of HPV DNA testing and liquid based cytology over three rounds of primary cervical screening: Extended follow up in the ARTISTIC trial.2011;47(6):864-871.

[9] Nwobodo H, Ba-Break M. Analysis of the determinants of low cervical cancer screening uptake among Nigeria women. J Pub Health Afri 2015; 6:484-492.

[10] Geremew AB, Gelagay AA, Azale T. Uptake of precervical cancer screening and associated factors among women aged 30-49 years in Finote Selam town North-West Ethiopia. Int J Coll Inter Med Pub Health 2018; 10(2):829-842.

[11] The cervical cancer screening programme, England 2017-2018, National statistics.

[12] Watson M, Benard V, Flagg EL. Assessment of trends in cervical cancer screening rates using healthcare claims data: United State, 2003-2014 Prev Med Rep 2018;9:124-130.

[13] Ncube BA, Bey A, Knight J. Factors associated with the uptake of cervical cancer screening among women in PortLand, Jamaica. J Med Sci 2015;7(3):104-113

[14] Owoeye IOG, Ibrahim IA. Knowledge and attitude towards cervical cancer screening among female students and staffs in a tertiary institution in the Niger Delta. Int J Med Res 2013; 2(1):48-50

[15] Elamurugan S, Rajendran P, Thangamani S. Cervical cancer screening: Awareness, attitude and practice of Indian women. Trop J Med Res 2016; 19:42-46.

[16] Moshi FV, Vandervort EB, Kibusi SM. Cervical cancer awareness among women in Tanzania: An analysis of data from 2011-2012 Tanzania HV and malaria indicators survey. Int J Chro Disea 2018; 1 7.

[17] Ogbonna FS. Knowledge, attitude and experience of cervical cancer and screening among sub-sahara Africa female students in a United Kingdom University. Ann Afri Med 2017; 16:1-23.

[18] Eze GU, Obiebi IP, Umuago IJ. Perspective of cervical cancer and screening practices among staff of a teaching hospital in south-south Nigeria. Jour Can Res Prac 2018; 5:67-73.

[19] Ebu NI. Socio-demographic characteristics influencing cervical cancer screening intention of HIV- positive women in the central region of Ghana. Gynae Onco Res Prac2018; 5:3-10.

[20] Hoque ME, Ghuman S, Coopoosmay R, Van Hal G. Cervical cancer screening among University Students in South Africa: A Theory based study. PloS ONE 2014;9(11):1-6.

[21] Ebu NI, Mupepi SC, Siakwa MP, Sampselle CM. Knowledge, practice and barriers toward cervical cancer in Elmina, Southern Ghana. Int J Women Health 2015; 7:31-39.

[22] Oluwole EO, Mohammed AS, Akinyinka MR, Salako O. Cervical cancer awareness and screening uptake among rural women in Lagos, Nigeria. J Comm Med Pr Heal Care 2017; 29(1):81-88.

[23] Assoumou SZ, Mabika BM, Mbiguino AN et al. Awareness and knowledge regarding cervical cancer, Pap smear screening and human papillomavirus infection in Gabonese women. BMC Women's Health 2015; 15:37-43.

[24] Bakari M, Takai IU, Bukar M. Awareness and utilization of Pap smear among Health workers in Maiduguri, North East Nigeria. Niger J Basic Clic Sci 2015; 12:34-38.

[25] Ifemelumma CC, Anikwe C, Okorochukwu BC et al. Assessment of perception and utilization of services among Health workers in low resource setting. Int J Repro Med 2019:1-8. 